\title{
ROLE OF PREOPERATIVE OESOPHGEALMANOMETRY IN OPERATIVE DECISION MAKING IN PATIENTS WITH CARDIAC ACHALASIA
}

\author{
Mohamed Farid Ahmed ${ }^{1}$, Mohammed Abd Elmegeed ${ }^{1}$, Rasha Samir ${ }^{2}$, \\ Amr Elhefny ${ }^{I}$, Khaled Elfeky ${ }^{I}$
}

\author{
${ }^{1}$ General surgery department, \\ Faculty ${ }^{2}$ Internal medicine \\ department, Faculty of Medicine, \\ Ain shams University, \\ Cairo, Egypt \\ Corresponding Author: \\ Mohamed Farid Ahmed \\ Mobile (+2) 01004161604 \\ E-mail: \\ mfaridsurg@gmail.com \\ Received: $16 / 6 / 2020$ \\ Accepted: 13/7/2020
}

Online ISSN: 2735-3540

\begin{abstract}
:
Background: Surgery is considered the treatment of choice for esophageal achalasia, since it provides symptomatic relief that is stronger and longer lasting. Laparoscopic Heller cardiomyotomy is the preferred treatment for an anti reflux surgery with found oplication. Preoperative HRM is essential to the detection of sufficient fundoplication.
\end{abstract}

Aim of the work: To assess the role of preoperative manometry in selection the type of antireflux surgery with Heller cardiomyotomy (Dor or Nissen fundoplication).

Patients and methods: This prospective cohort study was conducted on twenty (20) patients presented to Ain-Shams University hospitals outpatient clinics suffering from chronic dysphagia from January 2018 through January 2020 to assess the role of preoperative manometry in selection of operative type and decision making in treatment of achalasia.

Results: Using HRM ,14 patients (70\%) with type 1 achalasia underwent Dor fundoplication and in these Dysphagia and regurgitation improved substantially in patients ( $p$ value $=0.001$ and 0.001 respectively), also there were 4 patients (28.5\%) with post-operative reflux. 6 Patients (30\%) with type 2 achalasia underwent Nissen fundoplication and in these patients there was a significant improvement in dysphagia and regurgitation ( $p$ value $=$ 0.034 and 0.023 respectively), 3 patients (50\%) developed post-operative dysphagia, two of them improved on follow up. There was a significant reduction in LES pressure in both Dor and Nissen operation ( $p$ value $=0.001$ and 0.026 respectively).

Conclusion: Preoperative HRM is crucial in choosing type of fundoplication in achalasia as symptomatic responses vary depending on achalasia subtype.

Keywords: Achalasia, HRM, Nissen, Dor, Fundoplication.

\section{INTRODUCTION:}

Achalasia is a primary esophageal motor condition of unknown etiology characterized manometrically by inadequate relaxation of the lower esophageal sphincter (LES) and loss of esophageal peristalsis, radio graphically by aperistalsis, dilation of the esophagus, "bird-beak" appearance, delayed emptying of barium; and endoscopically by dilatation of the esophagus with remnant of saliva, liquid, and undigested food particles with no stricture or tumor ${ }^{[1]}$.

Achalasia spectrum disorders have been classified into clinically important subtypes based on esophageal motor patterns with high resolution manometry $(\mathrm{HRM})^{[2-4]}$. 
According to the Chicago classification of esophageal pressure patterns on HRM, achalasia is subtyped into the following; Type I (classic achalasia), Type II (pan-esophageal strain), Type III (spastic

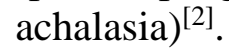

In particular, type II (panesophageal compartmentalization of intrabolus pressure $\geq 30 \mathrm{mmHg}$ in $\geq 20 \%$ test swallows) is associated with a slightly better response compared to Type I or Type III, whereas Type III (preserved but premature esophageal body peristalsis in $>20 \%$ test swallows) is associated with worse outcomes and may be the most difficult to manage ${ }^{[3]}$.

Since minimally invasive surgical procedures have been established, most authors agree that laparoscopic myotomy should be the first-line therapy with fundoplication; but the debate on the type of (partial or complete) fundoplicationstill controversial.

GERD is an important result parameter to be considered after myotomy, because the incidence of GERD symptoms and objective measurements of exposure to $24-\mathrm{h} \mathrm{pH}$ acid are higher without fundoplication. [5-6-7] [6-8-7]

This paper reports our experience with partial and total fundoplication after Heller myotomy according to the results of preoperative HRM.

\section{PATIENTS AND METHODS:}

Twenty patients were enrolled in a prospective study, presented to Ain-Shams University hospitals outpatient clinics suffering from chronic dysphagia from January 2018 through January 2020 to assess the role of preoperative manometry in selection of operative type and decision making in treatment of achalasia. Patients were assessed according to inclusion criteria and directed for preoperative manometry to determine proper operation that was done.
A comprehensive evaluation program was carefully structured so that each patient followed a consistent schedule. Both patients were evaluated both preoperatively and postoperatively. Ethical approval was obtained from the ethical committee of Ain Shams University and written consent was obtained from each patient after all aspects of the procedure were clarified, advantages, Disadvantages, reasonable standards and the risk of open surgery conversion and any intraoperative, early and late postoperative complications occurring. Throughout the research surgeries were conducted by the same surgical team.

Inclusion criteria included adult patients between 18 and 65 years of age with suspected achalasia who do not have an evidence of a mechanical obstruction on endoscopy with or without previous failed trials of dilatation.

Exclusion criteria, Patients who were unfit for general anesthesia, previous major upper abdominal surgeries or midline exploratory surgeries and pregnant females. Patients with esophageal strictures, diffuse ulceration and with dysphagia related to causes other than achalasia were also excluded.

\section{Patients were assessed clinically via history and examination for:}

1. Solid- and liquid dysphagia.

2. Partially digested food regurgitation.

3. Respiratory symptoms (aspiration and nocturnal cough).

4. Heartburn, chest pain.

5. Lost weight.

Investigations were done for all patients including:

1. Upper GI endoscopy: Comments on esophageal peristalsis and LES.

2. Barium study: Showed Smooth tapering of the lower esophagus leading to closed LES Similar to a "bird's beak'.' 
3. Oesophageal manometry (HRM): used for evaluation Esophageal peristalsis and lower pressure of the esophageal sphincter. Due to the risk of aspiration given the possibility of food content in the esophageal lumen due to motor changes, patients advised to fast for twelve hours; Suspension of drugs that can alter esophageal motility on the day of the examination (calcium channel blockers, nitrates, prokinetics, loperamide, opiates). Explanation of procedure and signed informed consent form. After calibration and cleaning the catheter was positioned when the lower and upper esophageal sphincters were identified on the screen. According to the results of preoperative high-resolution manometry patients were divided into two groups: Patients with type 1 achalasia where there is minimal contractile activity between the UES and EGJ. Those patients underwent Heller cardiomyotomy with Dor fundoplication. Patients with type 2 achalasia where there was $\geq 20$ percent of swallows (supine posture, $5 \mathrm{~mL}$ water) with pan esophageal pressurization to $\geq 30 \mathrm{mmHg}$. Those patients underwent Heller cardiomyotomy with Nissen fundoplication. (Fig. 1).

\section{Operative steps:}

All surgeries were done Laparoscopically. Patients placed in a supine, split leg. The patient is in a steep, reverse position in Trendelenburg. After inflation of the abdomen with Verses needle, four operating ports (two for the surgeon, one for the assistant and one for the scope) are positioned under clear vision, and liver retraction is then achieved by epigastric port retraction ( $S$ shaped). The initial dissection began on the right hand side of the esophageal suspension. The gastrohepatic ligament is incised in an avascular plane. Dividing the right anterior pharyngoesophageal ligament and the anterior abdominal esophagus peritoneum, retaining the anterior vagus nerve. Dividing the left phrenogastric ligaments by using Harmonic or Ligasurescalpel to separate the small gastric vessels; Beginning at the lower spleen pole to the left exposed diaphragm crus. The distal portion of the mediastinal esophagus is activated to achieve ample duration for an incision of the myotomy that separates the entire length of the LES. (Fig. 2).

On the esophagus a continuous myotomy was done for $6 \mathrm{~cm}$, and on the stomach for 3 $\mathrm{cm}$. The myotomy started over the gastroesophageal junction 1-2 $\mathrm{cm}$ above. (Fig. 3) Myotomy is performed longitudinally in the anterior axis of the esophagus using blunt dissection, electrical hook, scissors or a ligasure scalpel. Caution should be taken to avoid damage to the mucosa of the esophageal system. The longitudinal muscles are first separated then the circular one, showing a bulging mucosal plane that should appear white and smooth.

According to HRM results we performed dor or nissen fundoplication. The fundus was mobilized by separating the small gastric vessels and all the fundal attachments beginning roughly at the lower pole of the spleen, about 10 to $15 \mathrm{~cm}$ below His angle. The retroesophageal window is formed along the base of the left crus by further dissections.

After the mediastinal esophagus is activated, the gastroesophageal hiatus is subsequently closed with blocked, non-absorbable Ethibond 2-0 sutures but our choice is to leave the hiatus loose. The greater curve of the fundus is grasped with Dor (anterior) fundoplication and positioned anteriorly to the right side of the gastroesophageal hiatus. Fig. 4 In the Fundoplication of Floppy Nissen the posterior fundus is passed from left to right behind the esophagus. The anterior fundus is grasped $2 \mathrm{~cm}$ from the greater curvature to the gastroesophageal junction, and $3 \mathrm{~cm}$ distal. At the anterior part of the esophagus, it is then carried in before the esophagus to 
enter the posterior fundus. To prevent inclusion of the gastric body into the cover, the fundus must be grasped anteriorly and later at a place equidistant from the greater curvature. Three to four seromuscular sutures are positioned in 3 structures, from left to right. This is the anterior fundus, second is an esophagus seromuscular bite, and lastly, the posterior fundus. The first stitch is the suture most inserted in cephalad; its position is determined by the labelling stitch previously put. The remaining sutures are inserted sequentially to cover the intra-abdominal esophagus to a total of $3 \mathrm{~cm}$. Fig. 5 After the anti-reflux procedure has been completed, the area is tested for bleeding, hemostasis is achieved as required, the abdominal drain is inserted to the left side of the fundus, the liver retractor is removed and the port sites are all closed.

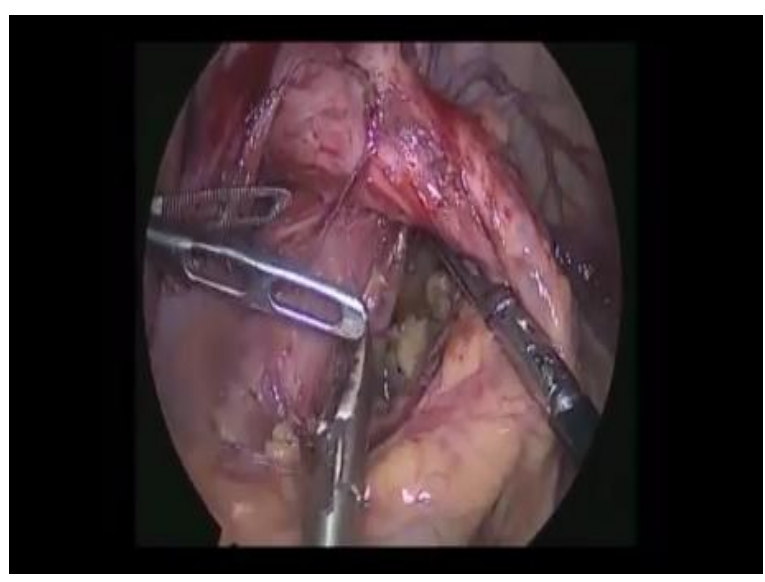

Figure 1: Myotomy dissection

\section{Outcome measures}

Clinical examination was performed at baseline and after surgery (pre-post), using a standardized rating system for DeMeester symptoms (Table 1), in which each patient was evaluated for three symptoms: dysphagia, regurgitation, and heartburn. Depending on its intensity a score of 0 to 3 was awarded for each symptom. Then a clinical score equal to the sum of each patient's symptom scores was finally determined, and then the reduction of each symptom severity was analyzed after the procedure. The score of Eckardt was also analyzed.

(Table2). For both forms of procedures, patients were tested for dysphagia and reflux. A distinction was made in the following 6-month pre-operative and post-operative parameters: DeMeester score, Eckardt score and LES pressure manometry finding.

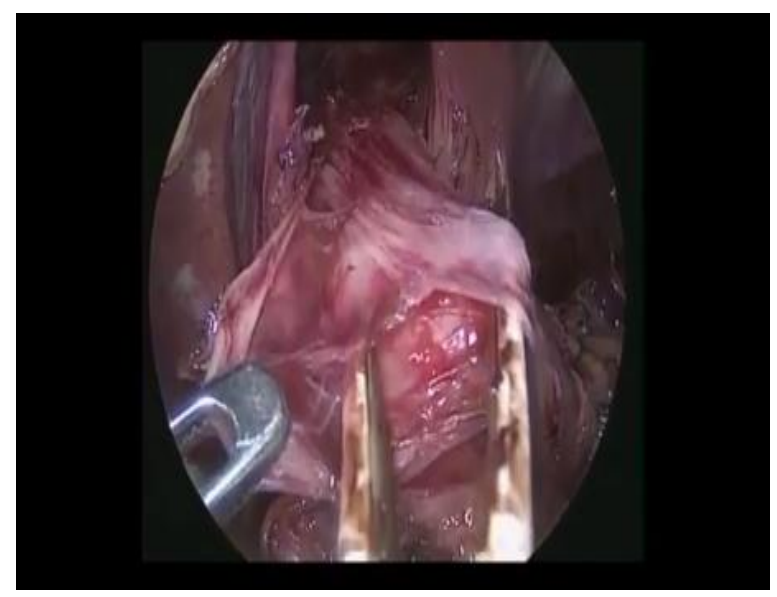

Figure 2: Fully mobilized esophagus 


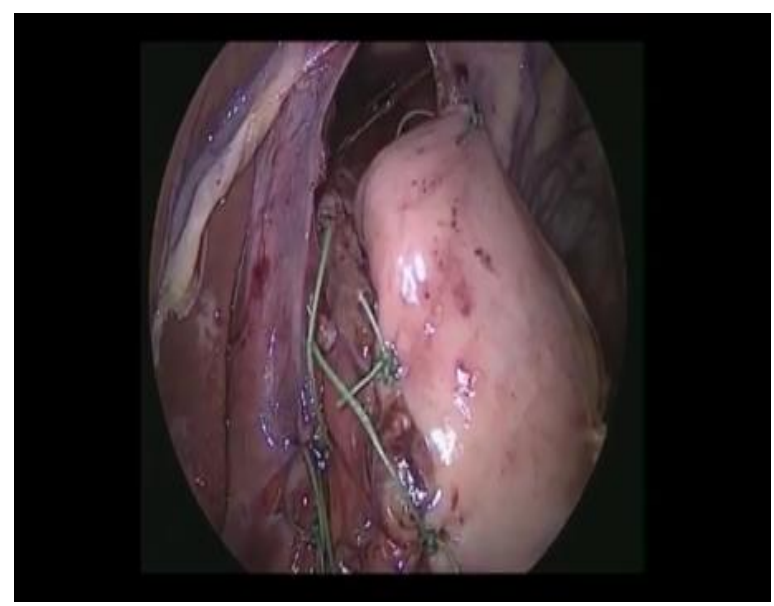

Figure 3: Anterior(Dor) fundoplication

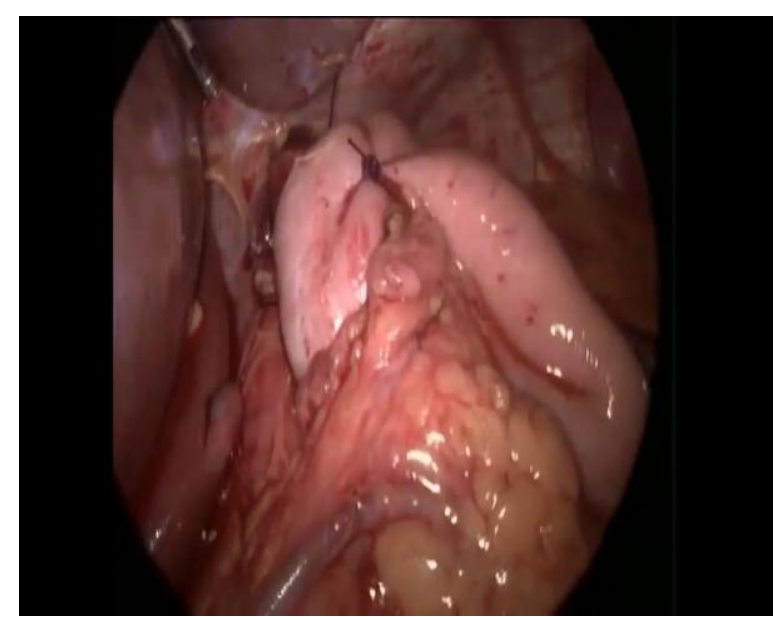

Figure 4: Nissen fundoplication

Table 1: De Meester score

\begin{tabular}{|l|l|l|}
\hline Symptom & Score & Description \\
\hline \multirow{4}{*}{ Dysphagia } & 0 & None \\
\cline { 2 - 3 } & 1 & Occasional transient episodes \\
\cline { 2 - 3 } & 2 & Require liquids to clear \\
\cline { 2 - 3 } & 3 & Impaction requiring medical attention \\
\hline \multirow{5}{*}{ Heart burn } & 0 & None \\
\cline { 2 - 3 } & 1 & Occasional brief episodes \\
\cline { 2 - 3 } & 2 & Frequent episodes requiring medical treatment \\
\cline { 2 - 3 } & 3 & Interference with daily activities \\
\hline & 0 & None \\
\cline { 2 - 3 } & 1 & Occasional episodes \\
\cline { 2 - 3 } & 2 & Predictable by posture \\
\cline { 2 - 3 } & 3 & Interference with daily activities \\
\hline
\end{tabular}

Table 2: Eckardt score for symptomatic evaluation in achalasia

\begin{tabular}{|c|c|c|c|c|}
\hline Score & Weight loss $(\mathrm{kg})$ & Dysphagia & Retrosternal Pain & Regurgitation \\
\hline 0 & None & None & None & None \\
\hline 1 & $<5$ & Occasional & Occasional & Occasional \\
\hline 2 & $5-10$ & Daily & Daily & Daily \\
\hline 3 & $>10$ & Each meal & Each meal & Each meal \\
\hline
\end{tabular}

\section{Statistical analysis:}

Tabulated data were obtained and analyzed statically. Data analysis was conducted using SPSS (Statistical Social Science Software version 26) as follows: Descriptive statistics (mean, standard deviation, range) were conducted for the patient characteristics and continuous variables. With the Shapira-wilk test quantitative data were checked for normality. Linked samples were used, using Wilcoxon Signed Rank Test. P-value $\leq 0.05$ was considered significant.

\section{RESULTS:}

In this study we had a total of 20 patients. They included $12(60 \%)$ females and 8(40\%) 
males, and the mean age was ( $38.75 \pm 6.92)$ and ranging from 26 to 50 years. We had 14 patients (70\%) with type 1 achalasia who underwent Heller cardiomyotomy and Dor fundoplication, and 6 patients (30\%) with type 2 achalasia who underwent Heller cardiomyotomy and Nissen fundoplication (Table3, Fig. 6).

Table3: Patient characteristics

\begin{tabular}{|l|l|c|}
\hline \multicolumn{2}{|c|}{ Characteristic } & NO(\%) /mean \pm SD \\
\hline $\begin{array}{l}\text { Age mean } \pm \text { SD (yrs.) } \\
\text { Range }\end{array}$ & & $\begin{array}{c}38.75 \pm 6.92 \\
(26-50)\end{array}$ \\
\hline Sex, female no (\%) & & $12(60 \%)$ \\
\hline BMI mean \pm SD & & $29 \pm 4.57$ \\
\hline Esophageal diameter No\% & Type 1 & $18(90 \%)$ \\
\cline { 2 - 3 } & Type 2 & $2(10 \%)$ \\
\hline LES Pressure mean \pm SD & & $36 \pm 3.01$ \\
\hline Esophageal motility No \% & Type 1 & $14(70 \%)$ \\
\cline { 2 - 3 } & Type 2 & $6(30 \%)$ \\
\hline Operation No \% & Dor & $14(70 \%)$ \\
\cline { 2 - 3 } & Nissen & $6(30 \%)$ \\
\hline
\end{tabular}

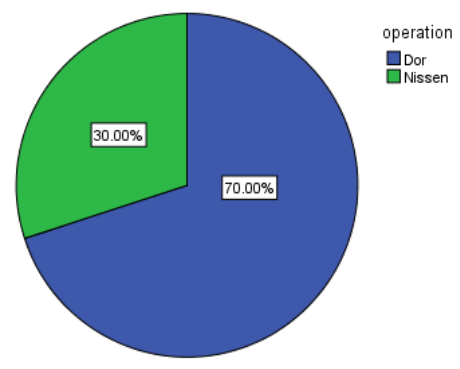

Figure 5: Dorvs Nissen.

On comparing preoperative and post-operative results for Dor fundoplication we found that there was significant improvement for dysphagia and regurgitation according to DeMeester score with $\mathrm{p}$ value $(0.001$ and 0.001$)$ respectively, but for heart burn the results was insignificant ( $\mathrm{p}$ value $=$ 0.480). Also, according to Eckardt score, the improvement was significant $(\mathrm{p}$ value $=$ 0.001). The difference in LES sphincter pressure also was significant ( $\mathrm{p}$ value $=$ 0.001) (Table 4).
On comparing preoperative and post-operative results for Nissen fundoplication we found that there was significant improvement for dysphagia and regurgitation according to DeMeester score ( $\mathrm{p}$ value $=0.034$ and 0.023 ) respectively, but for heart burn the results was insignificant ( $p$ value $=0.317)$. Also, according to Eckardt score the improvement was significant $(p$ value $=0.026$ ). The difference in LES sphincter pressure also was significant ( $p$ value $=0.026) .($ Fig 6 , Table 5$)$. 
Role Of Preoperative Oesophgeal Manometry In Operative Decision Making In Patients With ..

Table 4: Comparison between pre and postoperative findings in Dor fundoplication

\begin{tabular}{|l|c|c|c|}
\hline & Pre & Post & P value \\
\hline Dysphagia (DeMeester) & $2.79 \pm 0.43$ & $0.79 \pm 0.43$ & $0.001^{*}$ \\
\hline Heart burn (DeMeester) & $0.43 \pm 0.51$ & $0.29 \pm 0.47$ & $0.480^{*}$ \\
\hline Regurgitation (DeMeester) & $1.93 \pm 0.62$ & $0.29 \pm 0.47$ & $0.001^{*}$ \\
\hline Global score (DeMeester) & $5.07 \pm 0.73$ & $1.36 \pm 0.93$ & $0.001^{*}$ \\
\hline Eckardt score & $8 \pm 0.78$ & $1.21 \pm 0.89$ & $0.001^{*}$ \\
\hline LES sphincter pressure & $36.21 \pm 3.31$ & $12.79 \pm 0.67$ & $0.001^{*}$ \\
\hline
\end{tabular}

*Related-Samples Wilcoxon Signed Rank Test.

Table 5: Comparison between pre and postoperative findings in Nissen fundoplication

\begin{tabular}{|l|c|c|c|}
\hline & Pre & Post & P value \\
\hline Dysphagia (DeMeester) & $2.67 \pm 0.52$ & $1.67 \pm 0.82$ & $0.034^{*}$ \\
\hline Heart burn (DeMeester) & $0.5 \pm 0.55$ & $0.33 \pm 0.52$ & $0.317^{*}$ \\
\hline Regurgitation (DeMeester) & $2 \pm 0.63$ & $0.33 \pm 0.52$ & $0.023^{*}$ \\
\hline Global score (DeMeester) & $5 \pm 0.632$ & $2.33 \pm 0.52$ & $0.023^{*}$ \\
\hline Eckardt score & $8.17 \pm 0.75$ & $2.83 \pm 1.72$ & $0.026^{*}$ \\
\hline LES sphincter pressure & $35.5 \pm 2.35$ & $15.5 \pm 1.64$ & $0.026^{*}$ \\
\hline
\end{tabular}

*Related-Samples Wilcoxon Signed Rank Test.

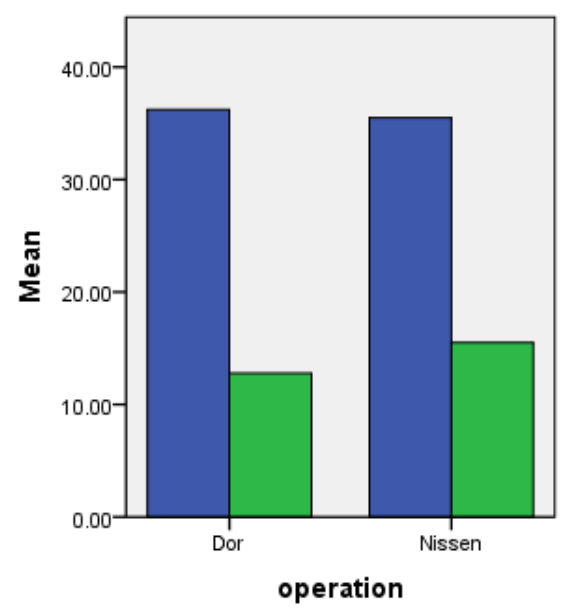

Figure 6: LES pressure pre and post.

Comparing post-operative dysphagia and reflux, there were 3 patients with dysphagia after Nissen fundoplication two of them improved on follow up. Also, there was only one patient with mild dysphagia after Table 6: Post operative Dysphagia and Reflux
Dor fundoplication. Considering reflux, there was no patients with reflux after Nissen fundoplication but there were 4 patients with reflux after Dor fundoplication two of them had mild symptoms (Table 6).

\begin{tabular}{|l|c|c|}
\hline & Dor & Nissen \\
\hline Dysphagia No \% & $3(50 \%)^{*}$ & $1(7.14 \%)$ \\
\hline RefluxNo \% & $0(0 \%)$ & $4(28.5 \%)$ \\
\hline
\end{tabular}

*Two patients improved during follow up.

The cumulative average length of the procedures was 94.29 minutes for operation in Dor and 130 minutes for operation in Nissen. Blood loss was minimal, and there were no transfusions. In Nissen there was one case of micro-perforations intraoperatively. The diagnosis was made during intraoperative digestive endoscopy and on the 
result of the procedure it was done with intraoperative suture of the perforation without sequelae. For both procedures, the median hospital stay was 2.54 days. (Table 7).

Table 7: Operative and post operative data

\begin{tabular}{|l|c|c|}
\hline & Dor & Nissen \\
\hline Surgical timemean \pm SD (min) & $114 \pm 24.6$ & $124.77 \pm 23.5$ \\
\hline Bleeding, mean \pm SD $(\mathrm{ml})$ & $28.42 \pm 39.4$ & $30.29 \pm 33.25$ \\
\hline Perforation NO & 0 & 1 \\
\hline Hospital stay, mean \pm SD (day) & $2.54 \pm 2.56$ & $2.54 \pm 2.76$ \\
\hline
\end{tabular}

\section{DISCUSSION:}

The etiology of esophageal achalasia remains elusive; medications presently available can only palliate the disease's usual symptoms by disturbing or splitting the unrelaxing LES muscle that is responsible for the condition. ${ }^{[6]}$

Surgery is considered the treatment of choice for esophageal achalasia as it provides a symptomatic relief that is greater and longer lasting than that achieved with medical or endoscopic care. ${ }^{[8-9]}$

Surgical therapy is based on extra mucosal esophageal myotomy, length of the myotomy and the type of the antireflux surgery (type of fundoplication) associated with myotomy is the controversial point of the procedure. ${ }^{[8]}$

The argument is to use the best surgical technique; in reality, if extra mucosal myotomy remains the standard treatment for resetting the lower esophageal sphincter pressure, it is still not known whether it is always necessary to combine antirefluxsurgery after myotomyor not, and if we will do such procedure which type of fundoplication is the best choice (partial versus complete rape).

GERD is an important result parameter to be considered after myotomy, because the incidence of GERD symptoms and objective measurements of exposure to 24-h $\mathrm{pH}$ acid are higher without foundoplication ${ }^{[10-16]}$.
As far as the requirement for fundoplication is concerned, almost all authors agree on the value of always performing anti-reflux fundoplication after esophageal myotomy, since it has been shown that myotomy alone associated with a high incidence of postoperative GERD that lead to a high risk of Barrett's esophagus. ${ }^{[13]}$

Instead, there are still contradictory opinions on the possibility of partial fundoplication (Dor) or complete (Nissen) ${ }^{[6]}$.

LHM with fundoplication has become a standard treatment for achalasia. It provides low morbidity rates, long-term symptoms of relief, and good quality of life. ${ }^{[10]}$

The development of high-resolution manometry catheters with 36 solid state sensors and software that graphically shows the topography of pressure has revolutionized the assessment of the function of the esophagus ${ }^{[15]}$.

The esophageal body and the upper and lower sphincters can now be tested simultaneously during HRM so that esophageal motility disorders can be defined more thoroughly ${ }^{[14]}$.

Achalasia reclassification was obtained and the most commonly known of these classification schemes is the "Chicago Classification' where Achalasia has three distinct sub-classes ${ }^{[14-15]}$.

This helps us to choose the appropriate type of anti-reflux procedure to be used with 
Heller myotomy to achieve symptomatic relief without reflux (GERD) or dysphagia depending on the esophagus' motility.

Amit et al, say that symptomatic responses differ according to the subtype of achalasia. Esophageal emptying can remain suboptimal in type I achalasia, where the esophageal body is dilated and potentially tortuous, so we prefer partial rape as an antireflux surgery with LHM $^{[11]}$.

Partial return of esophageal body peristalsis has been seen in type II achalasia, which may support esophageal emptying after HM. In addition, the esophageal body is not diluted and has tensile strength and a longitudinal muscle contraction which allows the production of hydrostatic pressure which can overcome residual resistance at the esophagogastric junction. These factors ensure a strong symptomatic response in type II achalasia when a full rape with LHM is performed $^{[11]}$.

Rossetti et al. ${ }^{[9]}$ reported a long-term follow-up of 195 consecutive laparoscopic procedures for treating esophageal achalasia with Heller myotomy plus fundoplication with Nissen-Rossetti. This strategy achieved a good outcomes with a 2.2 per cent occurrence of postoperative dysphagia and an absence of pathological GER in all 75 patients undergoing follow-up.

Our research showed that after Nissen fundoplication there were 3 patients with dysphagia, two of them improved on follow-up with $16.7 \%$ which is higher than that found in Rossetti et al 2.2\%. After Dorfundoplication there was only one patient with moderate dysphagia.

Considering reflux, there was no patients with reflux after nissen fundoplication similar to Rossetti et al and Antonello C et al, but there were 2 patients with reflux after dor fundoplication $14 \%$ similar to Gonzalo et al. $^{[5]}$

In 47.6 per cent of patients without fundoplication, Richards et al. 11 registered gastroesophageal reflux (GER), compared to 9.1 per cent with Dor fundoplication.

Falkenback et al. ${ }^{[17]}$ confirmed the existence of pathological reflux in 100 percent of patients who had only myotomy without antireflux versus 25 percent who had myotomy plus Nissen found oplication.

Campos et al. ${ }^{[12]}$ registered $31.5 \%$ pathological reflux without fundoplication and $8.8 \%$ with the Nissen technique These findings led to the clear recommendation of an LHM-associated with antireflux procedure and since have become the standard of care for patients with achalasia.

Our study revealed significant improvement in both dysphagia and regurgitation in both procedures Nissen and dor fundoplication with LHM but no significant difference reported in heart burn.

One limitation of our study is the subgroup analysis which is limited by the small sample sizes. On top of that there was a detection bias as the team wasn't blinded to the patient medical history and operation performed.

\section{Conclusion:}

Preoperative HRM is crucial in choosing type of fundoplication in achalasia. Our study appears to suggest that complete (nissen) and anterior partial (dor) fundoplication, performed for esophageal achalasia following Heller myotomy, showed similar long-term results in dysphagia. In addition, Nissen's fundoplication appears superior to Dor's in preventing postoperative esophageal acid reflux. Despite this, we maintain that the Dor fundoplication is the first-line of treatment for patients undergoing Heller myotomy for achalasia and we believe that GERD (its most frequent complication) that occur with dor can be managed pharmacologically with good patient compliance.

\section{Financial support and sponsorship:}

Nil 


\section{Conflicts of interest:}

There are no conflicts of interest

\section{Ethical Clearance:}

Cleared by the ethical committee of Department of General Surgery, Faculty of Medicine, Ain shams University, Cairo, Egypt No. IRB 00006379

\section{REFERENCES:}

1. Schlottmann F, Neto RML, Herbella FAM, Patti MG. Esophageal Achalasia: Pathophysio- logy, Clinical Presentation, and Diagnostic Evaluation. Am Surg. 2018; 84(4): 467-472.

2. Zaninotto G, Bennett C, Boeckxstaens G, et al. The 2018 ISDE achalasia guidelines. Dis Esophagus 2018; 31.

3. Kahrilas PJ, Bredenoord AJ, Carlson DA, Pandolfino JE. Advances in Management of Esophageal Motility Disorders. Clin Gastroenterol Hepatol. 2018; 16:1692.

4. Vaezi MF, Pandolfino JE, Vela MF. ACG clinical guideline: diagnosis and management of achalasia. Am J Gastroenterol 2013; 108:1238.

5. Gonzalo TV, Enrique CA, Janette FC, et al. DorVsToupet Fundoplication after Laparoscopic Heller Myotomy: Long-Term Randomized Controlled Trial Evaluated by High-Resolution Manometry. Journal of Gastrointestinal Surgery volume. 2018; 22: 13-22.

6. Antonello C, Antonio T, Angelo A, et al. Fundoplication After Heller Myotomy: A Retrospective Comparison Between Nissen and Dor. Eurasian J Med. 2011; 43(3):133-140. doi: 10.5152/eajm. 2011.31.

7. Kumagai K, Kjellin A, Tsai JA, Thorell A, Granqvist S, Lundell L, et al. Toupet versus Dor as a procedure to prevent reflux after cardiomyotomy for achalasia: results of a randomised clinical trial. International journal of surgery. 2014;12(7):673-80.

8. Rossetti G, delGenio G, Maffettone V, et al. Laparoscopic reoperation with total fundoplication for failed Heller myotomy: is it a possible option? Personal experience and review of literature. Int Surg. 2009; 94: $330-4$.

9. Rossetti G, Bruciano L, Amato G, et al. Total fundoplication is not an obstacle to esophageal emptying after Heller myotomy for achalasia. Results of a long-term follow-up. Ann Surg. 2005; 241:614-621.

10. Rawlings A, Soper NJ, Oelschlager B, et al. Laparoscopic Dor versus Toupet fundoplication following Heller myotomy for achalasia: results of a multicenter, prospective, randomized-controlled trial. Surg Endosc. 2012; 26:18.

11. Amit P, Ami P, Faiz A. M, et al. Achalasia symptom response after Heller myotomy segregated by high-resolution manometry subtypes. J Gastroenterol. 2016; 51(2): 112-118. doi: 10.1007/s00535-015-1088-6.

12. Campos GM, Vittinghoff E, Rabl C, et al. Endoscopic and surgical treatments for achalasia: a systematic review and metaanalysis. Annals of surgery. 2009;249(1): 45-57.

13. Richards WO, Torquati A, Holzman MD, et al. Heller myotomy versus Heller myotomy with Dor fundoplication for achalasia: a prospective randomized double-blind clinical trial. Ann Surg. 2004; 240:405.

14. Rohof W, Salvador R, Annese V, et al. Outcomes of treatment for Achalasia depend on manometric subtype. Gastroenterology. 2013; 144:718-725.

15. Roman S, Zerbib F, Quenehervé L, et al. The Chicago classification for achalasia in a French multicentric cohort. Dig Liver Dis 2012; 44:976.

16. Kumagai K, Kjellin A, Tsai JA, Thorell A, Granqvist S, Lundell L, et al. Toupet versus Dor as a procedure to prevent reflux after cardiomyotomy for achalasia: results of a randomised clinical trial. International journal of surgery. 2014;12(7):673-80.

17. Falkenback D, Johansson J, Oberg S, et al. Heller's esophagomyotomy with or without a 360 degrees floppy Nissen fundoplication for achalasia. Long- term results from a prospective randomized study. Dis Esophagus. 2003;16: 284-90. 


$$
\begin{aligned}
& \text { دور قياس حركية المرئ في مرضي الاكاليزيا وتاثرها علي القرار الجراحي }
\end{aligned}
$$

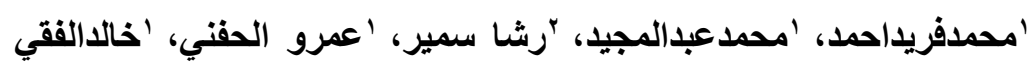

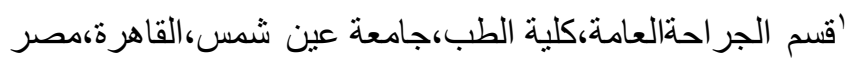

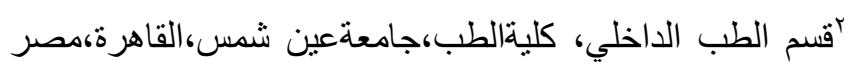

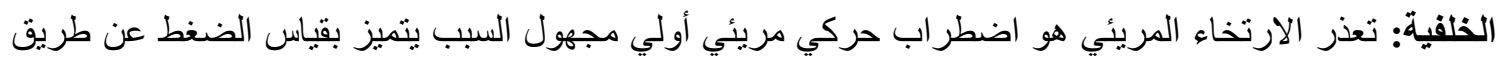

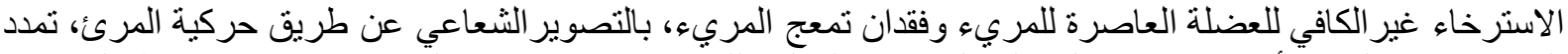

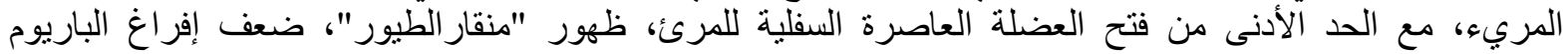

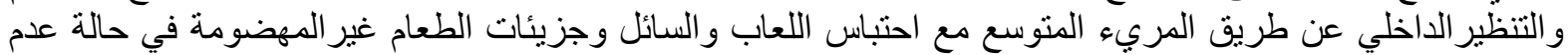
وجود هيكل أوورم مخاطي.

$$
\text { الهدف من العمل: دور قياس حركية المرئ في مرضي الاكاليزيا وتاثر ها علي القرار الجراحي }
$$

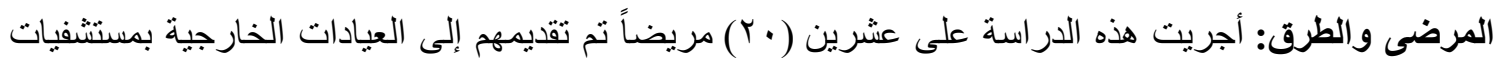

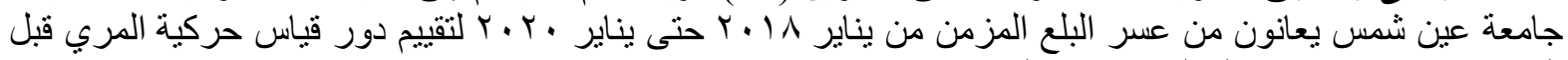

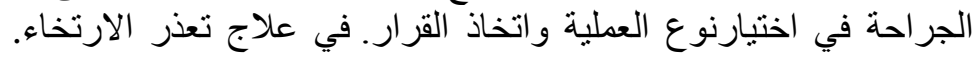

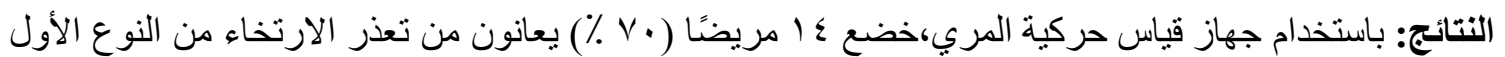

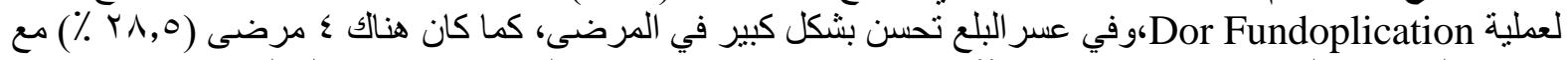

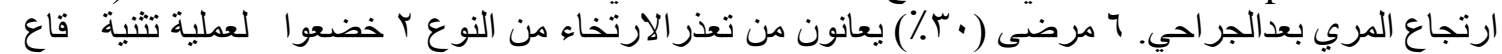

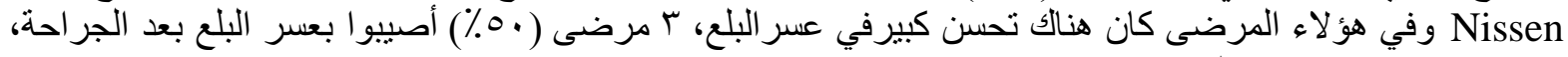
و اثثان من تحسينها عند المتابعة.

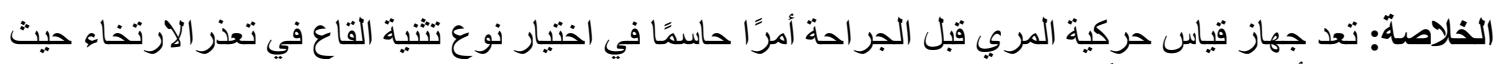

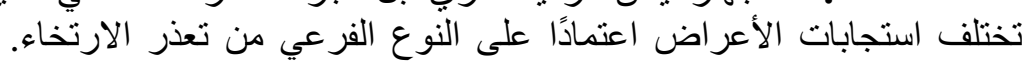

